\title{
Quantification of Industrial Wastewater Discharge From The Major Cities in Sichuan Province (China) From 2003 To 2018
}

\section{Zhen'an Yang ( $\sim$ yza2765@126.com )}

China West Normal University

\section{Yawen Zhang}

China West Normal University

Hui guo

China West Normal University

Zhaoxu Ma

China West Normal University

\section{Research Article}

Keywords: industrial wastewater, major cities, Sichuan province, LMDI

Posted Date: November 2nd, 2021

DOI: https://doi.org/10.21203/rs.3.rs-1025016/v1

License: (c) (i) This work is licensed under a Creative Commons Attribution 4.0 International License. Read Full License 
Quantification of industrial wastewater discharge from the major cities in Sichuan province (China) from 2003 to 2018

Zhen'an Yang ${ }^{1} \cdot$ Yawen Zhang ${ }^{1} \cdot$ Hui guo ${ }^{2} \cdot$ Zhaoxu Ma $^{1 *}$

1 Key Laboratory of Southwest China Wildlife Resources Conservation, Ministry of Education (China West Normal University), Nanchong, Sichuan, 637009, China

2 Administrative Office of Laboratory and Equipment, China West Normal University, Nanchong 637009, China

* Correspondence: zhaoxma@163.com 


\begin{abstract}
Wastewater discharge is produced as a side effect of socio-economic activities and exerts severe pressure on the environment, its characteristics depend on the rate of urbanization and industrialization. We used spatial autocorrelation, environmental Kuznets curve (EKC), and logarithmic mean Divisia index (LMDI) model to study the spatial characteristics and driving factors of industrial wastewater discharge in Sichuan province (2003-2018). We showed that the amount of industrial wastewater discharge in Sichuan province for the period was reduced from 116580 to 42064.96 million tons as observed from the Moran index ranging from -0.31 to 0.30 . We identified five types of the EKC (monotonically decreasing, N, inverted $\mathrm{N}, \mathrm{U}$, and inverted $\mathrm{U}$ shape) in 18 major cities of Sichuan province. The technical effect (from -0.28 to -16.37) can reduce the discharge of industrial wastewater, while structure effect (0.05-3.83), economy effect (0.19-7.79) and population effect (from -0.08 to 0.46 ) can promote the industrial wastewater discharge. Our findings suggest that industrial wastewater discharge was reduced and showed a scattered distribution characteristic in Sichuan Province from 2003 to 2018. It is necessary to strengthen technical management measures to reduce industrial wastewater discharge in Sichuan province.
\end{abstract}


The continuous global industrialization and urbanization have led to the production of large amounts of industrial wastewater in urban areas worldwide (Duttaa et al., 2021). For instance, the discharge of industrial water is 44 million cubic meters every day in India in 2014 (Ranade et al., 2014). It will not only pollute the surface water and groundwater, but also endanger human health when a large amount of industrial wastewater is discharged into the environment (Owodunni et al., 2021), such as diarrhea, malaria, and schistosomiasis (Jabeen et al., 2015). Even unsafe drinking water causes 2.2 million deaths from diarrhoea, 1.3 million from malaria and 160 million people are infected with schistosomiasis each year in the world (Jabeen et al., 2015). Given the complexity of pro-cessing technology and the high processing cost of industrial wastewater pollution (Jabeen et al., 2015), the reduction of industrial wastewater discharge is more important from practical perspective than its treatment. Due to this, numerous governments worldwide have implemented various effective measures to reduce the discharge of industrial wastewater (Keiser et al., 2018; Sun et al., 2021). For instance, the Clean Water Act was established by the United States to improve water quality in 1972 (Mao et al., 2021). The discharge of industrial wastewater was reduced by $45.6 \%$ in the industrial park of Tianjin's economic development area of China as a result of the overall management model for optimization of water resources (Geng et al., 2007). Additionally, the National Drinking Water Act was established to prevent water pollution in Pakistan in 2009 (Jabeen et al., 2015).

Understanding the characteristics of industrial wastewater discharge is basically the foundation for reducing the discharge of industrial wastewater (Ma et al., 2020). Previous studies often used spatial autocorrelation (Chen et al., 2016; 2019; Emrehan et al., 2018; Geng et al., 2014; Ma et al., 2020; Zhang et al., 2020), environmental Kuznets curve (EKC) (Abid 2015; Ajmi et al., 2015; Azam et al., 2016; Bimonte et al., 2017; Chen et al., 2016; Emrehan et al., 2018; Liu et al., 2015; Ma et al., 2020; Murshed et al., 2021; Pérez-Suárez et al., 2015; Zhou et al., 2013), and the logarithmic mean Divisia index (LMDI) model (Ajmi et al., 2015; Chen et al., 2016; Ma et al., 2020; Geng et al., 2014; Zhang et al., 2015) to quantify the characteristics, main drivers, and the relationship between industrial wastewater dis-charge and the process of urbanization. In particular, spatial autocorrelation (including global and local spatial autocorrelation) was applied to explain the relationship between variables and spatial distribution (Geng et al., 2014), such as previous study used spatial autocorrelation to explore the water resources utilization and its temporal and spatial characteristics in various provinces of Turkey from 2004 to 2014 (Emrehan et al., 2018). Moreover, the EKC was widely utilized to determine the relationship between environmental pollution and economic development (Ma et al., 2020; Murshed et al., 2021; PérezSuárez et al., 2015), such as carbon dioxide $\left(\mathrm{CO}_{2}\right)$ (Pérez-Suárez et al., 2015), PM2.5 (Zhang et al., 2019a), and sulfur dioxide $\left(\mathrm{SO}_{2}\right.$ ) (Ding et al., 2019). Moreover, the EKC is thought to have six types of correlations between environmental pollution and industrial wastewater discharge such as monotonically in-creasing, monotonically decreasing, $\mathrm{N}$ shape, inverted $\mathrm{N}$ shape, $\mathrm{U}$ shape, and inverted U shape (Abid 2015; Ajmi et al., 2015; Azam et al., 2016; Liu et al., 2015; Ma et al., 2020; Zhou et al., 2013). The monotonically decreasing, inverted $\mathrm{N}$ shape, and inverted U shape types indicate that the amount of industrial wastewater discharged eventually showed a decreasing trend with economic development (Abid 2015; Ma et al., 2020; Zhou et al., 2013). The monotonically in-creasing, $\mathrm{N}$ shape, and $\mathrm{U}$ shape types indicate that the amount of industrial wastewater discharged eventually exhibited a positive trend with an economic development (Abid 2015; Ma 
et al., 2020; Zhou et al., 2013). In general, spatial autocorrelation and the EKC can be used to study the relationship between industrial wastewater discharge and the economy, but they cannot explain the factors that affect industrial wastewater discharge (Guan et al., 2008, Xu et al., 2014; Zhuang et al., 28). To better understand the drivers of industrial wastewater discharge, the LMDI model was applied by researchers to study effects on industrial wastewater from technical, population, economic, and industrial perspectives (Mao et al., 2021; Geng et al., 2007; Emrehan et al., 2018; Chen et al., 2019; Jeong et al., 2013; González et al., 2014; Cansino et al., 2015; Román et al., 2018). For instance, some previous studies have concluded that the technical effect is the driving factor in reducing the discharge of industrial wastewater (Ma et al., 2020; Chen et al., 2016; 2019). Previous studies reported that technical effect is the main factor to reduce the discharge of industrial wastewater (Ma et al., 2020; Chen et al., 2016; 2019), and other studies believe that economic effect and urbanization effect will promote the discharge of industrial wastewater (Chen et al., 2016).

At the present stage, a large number of studies have been carried out on the discharge characteristics of industrial wastewater (Chen et al., 2016; 2019), driving factors (Chen et al., 2016; 2019) and its relationship with the urbanization process (Chen et al., 2016; 2019; Zhang et al., 2019b; Ran et al., 2019). However, most of these studies reveal the differences at the provincial scale (Chen et al., 2016; Ilyas et al., 2019) or region (Chen et al., 2019) to show the temporal and spatial dynamics of industrial wastewater discharge in a certain country, such as Pakistan (Román et al., 2018), China (Chen et al., 2016), and the Yangtze River Economic Zone (China) (Zhang et al., 2019b). However, the current development of refined urban management concept requires precise management measures based on the reality of each city (Ran et al., 2019; Zhang et al., 2019b), while previous large-scale research results have been unable to meet this demand. As the first and only province in western China with a GDP higher than the national average (Ma et al., 2020), Sichuan is home to more than 83.67 million people (The People's Government of Sichuan Province 2021a).Therefore, an accurate analysis of the spatial and temporal patterns and influencing factors of industrial wastewater in major cities in Sichuan province has a high reference value for other provinces in China and other developing countries in the world.

To this end, our study explored the spatial characteristics and driving factors of industrial wastewater discharge in Sichuan province by using spatial autocorrelation, environmental Kuznets curve (EKC), and LMDI model. The objectives were as follows: (1) to study the discharge characteristics of industrial wastewater in 18 major cities of Sichuan province (2003-2018), (2) to examine the driving factors of industrial wastewater discharge in 18 major cities of Sichuan province and (3) to propose tailored guidelines for environmental policy-making with regards to water quality based on our results.

\section{Materials and Methods}

\section{Data Sources}

The 18 major cities in Sichuan province including Chengdu:CD, Zigong:ZG, Panzhihua:PZH, Luzhou:LZ, Deyang:DY, Mianyang:MY, Guangyuan:GY, Suining:SN, Nei-jiang:NJ, Leshan:LS, Nanchong:NC, Meishan:MS,Yibin:YB, Guang'an:GA, Dazhou:DZ, Ya'an:YA, Bazhong:BZ, Ziyang:ZY and the four major economic zones of Sichuan prov-ince (the Chengdu 
plain economic zone:ECD, economic zone of southern Sichuan:ESS, northeast Sichuan economic zone:ENES, Pan-Xi economic zone:EXP) were selected for study. The cities of LS, GZ and AB were not considered due to insufficient data (Fig. 1). The industrial wastewater discharge data of Sichuan province, population, gross domes-tic product (GDP), GDP per capita, and added value of industry of Sichuan province were obtained from the 2004-2019 Sichuan Statistical Yearbook for this study. The industrial wastewater discharge data of major cities from 2004 to 2019 China City Statistical Yearbook.

\section{Global spatial autocorrelation}

We adopted the global spatial autocorrelation method to study the spatial distribution characteristics of industrial wastewater discharge. There are five indicators of spatial autocorrelation: $\mathrm{E}(I)$ is the value of mathematical expectation, $\mathrm{SD}$ is the standard deviation, $\mathrm{P}(I)$ is the significance level, $\mathrm{Z}$ represents the correlation between industrial wastewater and its location, and $\mathrm{I}$ is the Moran index (Ma et al., 2020; Chen et al., 2016). A Moran index $>0$ expresses a positive spatial correlation; the larger the value, the more prominent the agglomeration characteristics of the research subjects are (Ma et al., 2020; Chen et al., 2016; 2019). Moran index $<0$ reflects a negative spatial correlation; the smaller the value, the more prominent is the discrete feature of the object in space (Ma et al., 2020; Pérez-Suárez et al., 2015). A Moran index of 0 expresses a state of random distribution (Geng et al., 2014). Through the Geoda software, the analysis revealed that the industrial wastewater discharge of Sichuan province's 18 major cities is spatial-positive or spatial-negative in space. The equation was expressed as following (Eq. 1, Chen et al., 2016).

$$
I=\frac{n \sum_{i} \sum_{j} W i j(X \mathrm{i}-X)(X j-X)}{\left(\sum_{i} \sum_{j} W \mathrm{ij}\right) \sum_{i}(\mathrm{Xi}-X)^{2}}
$$

where $\mathrm{n}$ represents the number of study objects in this $\mathrm{W}_{\mathrm{ij}}$ study, represents the proximity of element $i$ and element $j$ in the space, $X_{i}$ represents the industrial wastewater discharge in city $i, X_{j}$ represents the industrial wastewater discharge in city $\mathrm{j}$, and $\mathrm{X}$ rep-resents the average estimate of industrial wastewater emissions of each city.

\section{Environmental Kuznets curve}

We used Statistical Package for the Social Sciences (SPSS) to explore the data and the relationship between industrial wastewater discharge and economic development in Sichuan province and 18 major cities. The expression can be established following previous study (Fosten et al., 2021; Ma et al., 2020) by Eq. (2), (3) and (4) below:

$$
\begin{aligned}
& Y_{i t}=\beta_{i}+\beta_{1 i} X_{\mathrm{it}}+\varepsilon_{\mathrm{it}} \\
& Y_{i t}=\beta_{0 i}+\beta_{1 i} X_{\mathrm{it}}+\beta_{2 \mathrm{i}} X_{i t}^{2}+\varepsilon_{i t} \\
& Y_{i t}=\beta_{0 i}+\beta_{1 i} X_{i t}+\beta_{2 i} X_{\mathrm{it}}^{2}+\beta_{3 \mathrm{i}} X_{i t}^{3}+\varepsilon_{i t}
\end{aligned}
$$

$\mathrm{Y}_{\text {it }}$ represents the industrial wastewater discharge of a province or a city in the year $t ; X_{i t}$ is the 
GDP of a province or city in the year t, $\varepsilon$ is an error term, $\beta_{0}$ is the intercept, and $\beta_{1 \mathrm{i}}, \beta_{2 \mathrm{i}}, \beta_{3 \mathrm{i}}$ are constant terms of the variables.

\section{Logarithmic Mean Divisia Index (LMDI)}

We applied the LMDI method to analyze the changes in industrial wastewater dis-charge in 18 major cities in Sichuan province from 2003 to 2018. The factors that affect industrial wastewater discharge include technical, structural, economic, and population effects. The equation was expressed as following (Eq. 5, Ma et al., 2020).

$$
\begin{aligned}
W^{t} & =\sum_{i}^{n} D_{i}^{t}=\sum_{i}^{n} \frac{W_{i}^{t}}{C_{i}^{t}} \cdot \frac{C_{i}^{t}}{G_{i}^{t}} \cdot \frac{G_{i}^{t}}{P_{i}^{t}} \cdot P_{i}^{t} \\
& =\sum_{i}^{n}\left(W_{i, e f f} \cdot W_{i, t e c} \cdot W_{i, e c o} \cdot W_{i, p o p}\right)
\end{aligned}
$$

where $\mathrm{W}^{\mathrm{t}}$ represents the total industrial wastewater discharge in year $\mathrm{t} ; \mathrm{C}_{\mathrm{i}}$ represents the total amount of urban domestic sewage discharge of the city $i ; G_{i}$ is the gross regional product and represents the total population of the city $\mathrm{i} ; \Delta \mathrm{W}_{\mathrm{i}}^{\mathrm{t}}$ represents the industrial wastewater discharge of the city $\mathrm{i}$ in the year $\mathrm{t}$; and $\mathrm{W}_{\mathrm{t}}^{0}$ represents the industrial wastewater discharge of the city $\mathrm{i}$ in the base year.

According to the LMDI type of the total contribution decomposition equation, the contribution of each factor to the sewage discharge intensity is obtained (Ran et al., 2019). The equation was expressed as following (Eq. 6, 7, 8 and 9).

$$
\begin{aligned}
\Delta W_{\text {tec }, i} & =\frac{W_{i}^{t}-W_{i}^{0}}{\ln W_{i}^{t}-\ln W_{i}^{0}} \cdot \ln \left(\frac{W_{\text {tec }, i}^{t}}{W_{\text {tec }, i}^{0}}\right) \\
\Delta W_{s t r, i} & =\frac{W_{i}^{t}-W_{i}^{0}}{\ln W_{i}^{t}-\ln W_{i}^{0}} \cdot \ln \left(\frac{W_{\text {str }, i}^{t}}{W_{\text {str }, i}^{0}}\right) \\
\Delta W_{e c o, i} & =\frac{W_{i}^{t}-W_{i}^{0}}{\ln W_{i}^{t}-\ln W_{i}^{0}} \cdot \ln \left(\frac{W_{e c o, i}^{t}}{W_{e c o, i}^{0}}\right) \\
\Delta W_{p o p, i} & =\frac{W_{i}^{t}-W_{i}^{0}}{\ln W_{i}^{t}-\ln W_{i}^{0}} \cdot \ln \left(\frac{W_{p o p, i}^{t}}{W_{p o p, i}^{0}}\right)
\end{aligned}
$$

$\Delta \mathrm{W}_{\text {tec, } \mathrm{i}}$ represents the contribution of science and technology to industrial wastewater discharge, Wttec,i represents the ratio of industrial wastewater discharge and industrial added value in the $t$ th year of the $i$ th city; $\mathrm{W}_{\text {teci }}^{0}$ represents the ratio of the annual industrial wastewater discharge and industrial added value of the $i$ th city of the base year. $\Delta \mathrm{W}_{\text {str, }}$ represents the contribution value of industrial structure to industrial wastewater, $\mathrm{W}_{\mathrm{stri}, \mathrm{i}}^{\mathrm{t}}$ represents the ratio of industrial added value to regional GDP of the $i$ th city in year $\mathrm{t}, \mathrm{W}_{\text {0str, }}$ represents the ratio of industrial added value and regional GDP of the $i$ th city of the base year. $\Delta \mathrm{W}_{\text {eco, }}$ represents the contribution value of economic development to industrial wastewater discharge, $\Delta \mathrm{W}^{0}{ }_{\text {eco, }}$ represents the ratio of the regional GDP of the $i$ th city in the $t$ th year, the total population of the $i$ th city in the $t$ th year, and $\mathrm{W}_{\text {teco,i }}$ represents the ratio of GDP of the $i$ th city region to the total population of the $i$ th city in the base year, $\Delta \mathrm{W}_{\mathrm{pop}, \mathrm{i}}$ 
is the contribution value of the total population to industrial wastewater discharge, $\mathrm{W}_{\mathrm{pop}, \mathrm{i}}^{\mathrm{t}}$ represents the total population of the $i$ th city in the $t$ th year, and $\mathrm{W}^{0}{ }_{\mathrm{pop}, \mathrm{i}}$ represents is the total population of the $i$ th city in the base year.

The contribution value of the industrial structure effect, economic effect, and population effect on the discharge of industrial wastewater is greater than 0 , indicating that industrial organization, economic, and population effects promote the discharge of industrial wastewater.

\section{Results}

\section{Spatio-temporal variation of industrial wastewater discharge}

The total amount of industrial wastewater discharged in Sichuan decreased from 116580 million tons in 2003 to 42064.96 million tons in 2018, and peaked at 118130 million tons in 2005 (Fig. 2). The discharge of industrial wastewater in the ECD and ENES exhibited a downward trend from 2003 to 2018 (Fig. 2). The discharge of industrial wastewater in the EXP exhibited a decreasing trend from 2003 to 2011 and an increasing trend from 2012 to 2018 (Fig. 2). The discharge of industrial wastewater in the ESS has been fluctuating between 2003 and 2018 (Fig. 2) The major cities of CD, ZG, LZ, GY, SN, NJ, LS, NC, DZ, YA, and ZY exhibited a decreasing trend in industrial wastewater discharge from 2003 to 2018 (Table S1). The industrial wastewater discharge of PZH first decreased, but then increased in 2003-2018 (Table S1). The cities of DY, MY, MS, YB, BZ, and GA exhibited a positive trend first, further, shifting to a negative trend in 2003-2018 (Table S1).

\section{Analysis of Global Spatial Autocorrelation of industrial wastewater discharge}

The Moran index of industrial wastewater discharge in Sichuan province ranged from -0.310 to 0.302 in 2003-2018 and was significant (Table 1). From 2011-2014, the Moran index of industrial wastewater discharge in the four major economic zones of Sichuan Province varied between 0.11 and -0.30 which indicated that the discharge of industrial waste water in the four economic zones showed discrete state during this period (Table S1). The Moran index of industrial wastewater discharge in Sichuan province ranged from -0.112 to -0.159 in 2015-2018, which indicated that the discharge of industrial waste water in the four economic zones showed discrete state during this period (Table 1).

\section{Analysis of EKC of industrial wastewater discharge}

The EKC curve of the total amount of industrial wastewater discharged and the economy of Sichuan province shows a monotonic decreasing shape (Table 2). Among the 18 major cities, the EKC curves of industrial wastewater discharge and economic growth of $\mathrm{CD}, \mathrm{NJ}$, LS and ZG are monotonically decreasing (Table 2). The EKC curves of industrial wastewater discharge and economic growth of LZ, GY, SN and MS are U-shaped (Table 2). The EKC curves of industrial wastewater discharge and economic growth of DZ, YA, BZ, ZY and MY are inverted $\mathrm{N}$ shape (Table 2). The EKC curves of industrial wastewater discharge and economic growth of PZH, YB, DY and NC are N shape (Table 2). Only the EKC curve of industrial wastewater discharge and economic growth in GA presents an inverted U shape (Table 2). 


\section{Analysis of logarithmic mean Divisia index of industrial wastewater discharge}

The results showed that the contribution value of technological effect to industrial wastewater discharge is $<0$, while the contribution value of structural effect and economic effect to industrial wastewater discharge is $>0$ from 2003 to 2018 (Fig. 3). The contribution value of population effect to industrial wastewater discharge in $\mathrm{ZY}, \mathrm{SN}, \mathrm{ZG}$ and NJ is $>0$ (Fig. 3). However, the contribution value to the industrial wastewater discharge of CD, DY, MY, LS, MS, YA, LZ, YB, DA, NC, GA, BZ, DZ and PZH is < 0 (Fig. 3). Our results demonstrated that the technical effect had the highest contribution to the discharge of industrial wastewater $(-0.28$ to -16.37$)$, followed by the structure effect ( 0.05 to 3.83 ), the economic effect ( 0.19 to 7.79 ), whereas the population effect (-0.08 to 0.46$)$ had the least contribution to industrial wastewater discharge (Fig. 3).

\section{Discussion}

\section{Spatio-temporal characteristics of industrial wastewater discharge}

The amount of industrial wastewater discharged from Sichuan province have decreased from 116580 million tons to 42064.96 million tons from 2003 to 2018 (Table 1). The main driver of this decrease was seemingly the implementation of energy conservation, and emissionreduction, that had been previously introduced by the Sichuan Provincial Government (Zhang et al., 2020). The chemical oxygen demand decreased by $5.43 \%$ due to the development of a circular economy model from 2006 to 2010 (Ghisetti and Quatraro 2017).

Our results further showed that the industrial wastewater discharge of ECD, ESS, and ENES was reduced by $70 \%, 59 \%$, and $76 \%$, respectively, while the industrial wastewater discharge of EXP (PZH) increased by 73\% (Fig. 2). Most of the cities with high discharge of industrial wastewater are concentrated in the ECD (Fig. 2), thus resonating with some previous studies. In particular, a previous study has reported that the areas of high industrial wastewater discharge are mainly characterized by relatively developing economies, large populations, and high industrialization (Zhou et al., 2013). Therefore, it is necessary to properly control the population and adjust the industrial structure to reduce the discharge of industrial waste water in cities with high discharge of industrial waste water. Since the chemical industry can promote the discharge of industrial waste water, while the mining industry has little influence on the discharge of industrial waste water, the industrial structure can be adjusted by reducing the proportion of chemical industry (Claudia et al., 2017; Ma et al., 2020; The People's Government of Sichuan Province 2021b).

The Moran index was previously used to evaluate the spatial agglomeration characteristics of pollutant emissions (Ma et al., 2020). For instance, a previous study concluded that Tur-key's provincial water consumption changed from 0.1286 to -0.025 from 2004 to 2014, thus, suggesting that the distribution pattern of areas with high water consumption changed from agglomeration to dissociation (Chen at al., 2016). The Moran index of most major cities in this study was < 0 (Table 1), indicating that the discharge of industrial wastewater has spatial discrete characteristics in most of the 18 major cities in Sichuan province. Therefore, each city should formulate corresponding emission reduction measures according to the specific situation of local industrial wastewater discharge (Emrehan et al., 2018). 


\section{Environmental Kuznets curve changes of major industrial cities}

As mentioned, the EKC can be utilized as an indicator for studying the relationship between environmental pollution and economic development (Pérez-Suárez et al., 2015; Lu et al., 2021). Moreover, previous studies have found that the EKC curve of environmental pollution and economic development exhibits not only an inverted U shape (Ajmi et al., 2015; Azam et al., 2016; Bimonte et al., 2017; Liu et al., 2015). From this standpoint, we found that the EKC curve of total industrial wastewater discharge and economic growth in Sichuan Province is monotonically decreasing (Table 2). The EKC of industrial wastewater discharge and economic growth in the 18 major cities of Sichuan province has five types: monotonous decreasing shape (CD, NJ, ZG and LS), N shape (DZ, YA, BZ, ZY, and MY), inverted N shape (PZH, DY, NC and YB), U-shaped (LZ, GY, SN and MS), and inverted U shape (GA) (Table 2). The types of EKC are monotone decreasing type; inverted $\mathrm{N}$ and inverted $\mathrm{U}$ type represent decreasing industrial wastewater discharge with economic growth (Table 2) (Zhou et al., 2013). In turn, this emphasizes that the pollution caused by the discharge of industrial wastewater from these cities $(\mathrm{CD}, \mathrm{NJ}, \mathrm{ZG}, \mathrm{LS}$, PZH, DY, NC, YB, and GA) have been improved to a certain extent. These cities can achieve the emission reduction of industrial wastewater as long as they continue to implement the policies and measures of industrial wastewater discharge management formulated at the present stage in the future development process (Chen et al., 2016; Ma et al., 2020). However, the types of EKC are N and $\mathrm{U}$ types expressing that industrial wastewater discharge is increasing with economic growth (Table 2) (Murshed et al., 2021). This finding suggests that the pollution driven by the discharge of industrial wastewater from these cities (DZ, YA, BZ, ZY, MY, LZ, GY, SN, and MS) was owing to the effective measures to improve the pollution in a timely manner. Thus far, these cities need to formulate relevant policies to control water pollution and achieve green development in accordance with environmental changes (The People's Government of Sichuan Province 2021b).

\section{Analysis of Driving Factors of Industrial Wastewater Discharge in Major Cities}

A previous study has concluded that population, economy, and urbanization level were the main drivers of industrial wastewater pollution (Zhang et al., 2020). Moreover, many studies have analyzed the drivers of industrial wastewater using LMDI (Chen et al., 2013; Geng et al., 2007; 2014; Ma et al., 2020). For example, some studies have found, by using LMDI, that economic or technical effects are the main factors influencing the industrial wastewater discharge of Chinese provinces (Chen et al., 2013; Geng et al., 2014). The same result has been reported for industrial wastewater discharge in the Yangtze River Economic Zone from 2002 to 2015 (Chen et al., 2019). Meanwhile, our results indicated that technical effect is the main factor in the reduction of industrial wastewater discharge in 18 major cities in Sichuan province (from -0.28 to -16.37) (Fig. 3). Although previous studies have shown that technical effects have a limited impact on the reduction of industrial wastewater discharge (Ma et al., 2020), Sichuan province still needs to import foreign advanced wastewater treatment in the future (Chen et al., 2016). For instance, both physical treatment technologies (adsorption, chemical treatment technologies such as coagulation and flocculation), biological treatment technologies (activated sludge or biofilm) and wastewater reuse technology should be adapted (Mao et al., 2021; Sathaiah and Chandrasekaran 2020).

The industrial structure effect (from 0.05 to 3.83 ), economic effect (from 0.19 to 7.79 ), and population effect (from -0.08 to 0.46 ) will increase the discharge of industrial wastewater 
according to the current study (Fig. 3). Enterprises need to transform from an industrial economy to a service economy (Geng et al., 2014; Ma et al., 2020) since previous studies have shown that the adjustment structure of industry (Lu et al., 2020; Zhang et al., 2021). As the economic effect can also promote the discharge of industrial wastewater, we need measures to reduce the discharge of industrial wastewater including increasing investment in sewage treatment facilities for encouraging technical innovation, and continuous amelioration of sewage treatment equipment to ensure economic development and reduce the discharge of industrial wastewater (Chen et al., 2016). The results further indicate that the population effect of most cities can also promote the discharge of industrial wastewater (Fig. 3). Therefore, enterprises must frequently carry out the activities broadening the knowledge about scientific and industrial aspects of wastewater. This will help promoting wastewater treatment knowledge among residents and will reward those who report illegal discharge of industrial wastewater (Ma et al., 2020; Chen et al., 2019).

\section{Conclusions}

This study uses spatial autocorrelation, EKC, and LMDI models to analyze the spatiotemporal characteristics and influencing factors of industrial wastewater discharge in 18 major cities and four major economic zones in Sichuan Province (China) in 2003-2018. Our results showed that (1) the discharge of industrial wastewater and the Moran index decreased from 116580 million tons to 42064.96 million tons and from- 0.310 to 0.302 , respectively. The EKC curve of Sichuan's industrial wastewater discharge and economy is monotonically decreasing. (2) The industrial wastewater in major cities and the four major economic zones showed an overall downward trend (513.37, 170.98 and 89.56 million tons for ECD, ESS and ENS, respectively). Despite this, industrial wastewater discharge has increased by millions of tons. (3) The EKC of industrial wastewater discharge and economic development in major cities are monotonically decreasing (CD, NJ, ZG, LS), N shape (DZ, YA, BZ, ZY, MY), inverted N shape (PZH, DY, NC, YB), U-shape (LZ, GY, SN, MS), and inverted U-shaped (GA). (4) During the study period, technical effects were the major contributions of the discharge (from -0.28 to -16.37), followed by economic effects (from 0.19 to 7.79), industrial structure effects (from 0.05 to 3.83), and population effects (from -0.08 to 0.46 ). These results suggest that from 2003 to 2018, the total amount of industrial wastewater discharge in Sichuan province exhibited a decreasing trend, whereas the technical effect played a significant role in reducing industrial wastewater discharge.

Supplementary Materials The following are available online at www.mdpi.com/xxx/s1, Table S1: Industrial wastewater discharge in 18 major cities of Sichuan province 2003-2018.

Acknowledgments The research was financially supported by the Scientific Research Foundation of China West Normal University [18Q045, 18Q044]. We thanks Mr. Lin Jiang for his help with the production of Fig. 1 by ArcGIS. And we also thank Editage (www.editage.cn) for English language editing and very grateful to the editor and the anonymous reviewers for their helpful and constructive comments and suggestions that greatly improved this manuscript.

Availability of Data and Materials Data, associated metadata, and calculation tools are available from the corresponding author.

\section{Declarations}


Conflicts of Interest The authors declare that they have no conflict of interest.

\section{References}

Abid M (2015) The close relationship between informal economic growth and carbon emissions in Tunisia since 1980: the (ir) relevance of structural breaks. Sustain Cities Soc 15:11-21.

Ajmi AN, Hammoudeh S, Nguyen DK, Sato JR (2015) On the relationships between $\mathrm{CO}_{2}$ emissions, energy con-sumption and income: The importance of time variation. Energ Econ 49:629-638.

Azam M, Khan AQ (2016) Testing the Environmental Kuznets Curve hypothesis: A comparative empirical study for low, lower middle, upper middle and high income countries. Renew Sust Energ Rev 63:556-567.

Bimonte S, Stabile A (2017) Land consumption and income in Italy: a case of inverted EKC. Ecol Econ 131:36-43.

Cansino JM, Sánchez-Braza A, Rodríguez-Arévalo ML (2015) Driving forces of Spain's $\mathrm{CO}_{2}$ emissions: A LMDI decomposition approach. Renew Sust Energ Rev 48:749-759.

Chen KL, Liu XQ, Ding L, Huang GZ, Li ZQ (2016) Spatial characteristics and driving factors of provincial wastewater discharge in China. Int J Env Res Pub He 13:1221.

Chen KL, Guo YQ, Liu XQ, Gui J, Zhang Z (2019) Spatial-temporal pattern evolution of wastewater discharge in Yangtze River Economic Zone from 2002 to 2015. Phys Chem Earth 110:125 - 132

Ding X, Zhou JG, Qiao J, Le T (2019) Spatial dependence of Environmental Kuznets Curve of industrial atmospheric pollutants in North China. J Hebei GEO Univ 42:75-82 (in Chinese).

Duttaa D, Aryab S, Sunil K (2021) Industrial wastewater treatment: Current trends, bottlenecks, and best practices. Chemosphere 285:131245.

Emrehan AF, Yildiz D, Günes MS (2018) A spatio-temporal approach to national natural resources: the change of provincial water use over Turkey. Sigma J Eng Nat Sci 36 (2):539-551.

Fosten J, Morley B, Taylor T (2021) Dynamic misspecification in the environmental Kuznets curve: Evidence from $\mathrm{CO}_{2}$ and $\mathrm{SO}_{2}$ emissions in the United Kingdom. Ecol Econ 76:25-33.

Geng Y, Cote R, Tsuyoshi F (2007) A quantitative water resource planning and management model for an industrial park level. Reg Environ Change 7:123-135.

Geng Y, Wang ML, Sarkis J, Xue B, Zhang L, Fujita T, Yu XM, Ren WX, Zhang LM, Dong HJ (2014) Spatial-temporal patterns and driving factors for industrial wastewater emission in China. J Clean Prod 132:1-13.

Ghisetti C, Quatraro F (2017) Green technologies and environmental productivity: A cross sectoral analysis of direct and indirect effects in Italian regions. Ecol Econ 132:1-13.

González PF, Landajo M, Presno MJ (2014) Tracking European Union $\mathrm{CO}_{2}$ emissions through LMDI (logarithmicmean Divisia index) decomposition. The activity revaluation approach. Energy 73:741-750.

Guan D, Hubacek K, Weber C, Peters G, Reiner DM (2008) The drivers of Chinese $\mathrm{CO}_{2}$ emissions from 1980 to 2030. Global Environ Chang 18(4):626-634.

Ilyas M, Ahmad W, Khan H, Yousaf S, Yasir M, Khan A (2019) Environmental and health impacts of industrial wastewater effluents in Pakistan: a review. Rev Environ Health 34:171-186 .

Jabeen A, Huang XS, Aamir M (2015) The challenges of water pollution, threat to public health, flaws of water laws and policies in Pakistan. J Water Resour Prot 7:1516-1526. 
Jeong K, Kim S (2013) LMDI decomposition analysis of greenhouse gas emissions in the Korean manufacturing sector. Energ Policy 62:1245-1253.

Keiser DA, Shapiro JS (2018) Consequences of the clean water Act and the demand for water quality. Q J Econ 134 (1):349-396.

Liu YS, Zhou Y, Wu WX (2015) Assessing the impact of population, income and technology on energy consumption and industrial pollutant emissions in China. Appl Energ 155:904-917.

Lu LY, He JL, Zeng G (2020) Decoupling of economic growth and industrial wastewater discharges from an innovation-driven perspective: Taking the Yangtze River Delta Urban agglomeration as an example. Areal Res Dev 39(5):156-162 (in Chinese).

Ma BR, Tian GJ, Kong LQ (2020) Spatial-temporal characteristics of China's industrial wastewater discharge at different scales. Environ Sci Pollut R 27:8103-8118.

Mao GZ, Hu HQ, Liu X, Crittenden J, Huang N (2021) A bibliometric analysis of industrial wastewater treatments from 1998 to 2019. Environ Pollut 275:1157785.

Murshed M, Alam R, Ansarin A (2021) The environmental kuznets curve hypothesis for Bangladesh: the importance of natural gas, liquefied petroleum gas, and hydropower consumption. Environ Sci Pollut R 28:17208-17227.

Owodunni AA, Ismail S (2021) Revolutionary technique for sustainable plant-based green coagulants in industrial wastewater treatment—A review. J Water Process Eng 42:102096.

Pérez-Suárez R, López-Menéndez AI (2015) Growing green? Forecasting $\mathrm{CO}_{2}$ emissions with environmental Kuznets curves and logistic growth models. Environ Sci Policy 54:428-437.

Ranade VV, Bhandari VM (2014) Industrial wastewater treatment, recycling, and reuse. Elsevier Butterworth-Hein, United Kingdom.

Ran XJ (2019) Analysis of fine urban design and management in China. Construction and Decoration 15:142-143 (in Chinese).

Rey SJ, Anselin L (2001) Recent advances in software for spatial analysis in the social sciences. environmental Kuznets curve: Testing advancement to carbon intensity-oriented sustainability for eight economic zones in China. J Clean Prod 283.

Román R, Cansino JM, Rodasa JA (2018) Analysis of the main drivers of $\mathrm{CO}_{2}$ emissions changes in Colombia (1990-2012) and its political implications. Renew Energ 116:402-411.

Sathaiah M, Chandrasekaran M (2020) A bio-physical and socio-economic impact analysis of using industrial treated wastewater in agriculture in Tamil Nadu, India. Agr Water Manage 241:106394.

Sun H, Ni S, Zhao TX, Huang C (2021) The transfer and driving factors of industrial embodied wastewater in China's interprovincial trade. J Clean Prod 317:128298.

The People's Government of Sichuan Province (2021a). Press conference on the main data results of the seventh National population census in Sichuan Province. http://www.sc.gov.cn/10462/10705/10707/2021/5/27/3ef3323416694f98a236021554b82406. shtml (Accessed 22 May 2021).

The People's Government of Sichuan Province (2021b). The fourteenth Five-year Plan for National Economic and Social Development of Sichuan Province and the outline of the Long-term Goals of 2035. http://www.sc.gov.cn/10462/c108548/2021/3/17/fbd667c2dc65456886fcb0992f0e8525.shtml (Accessed 22 May 2021).

Xu S,C He ZX, Long RY (2014) Factors that influence carbon emissions due to energy 
consumption in China: decomposition analysis using LMDI. Appl Energ 127:182-193.

Zhang HC, Cheng CQ, Miao SX (2019) A precise urban component management method based on the GeoSOT Grid Code and BIM. ISPRS Int J Geo-Inf 8:159.

Zhang PY, Dan YG, Yu ZG, Li YY, Liu Y, Cen YF, Wei ZG, Geng WL, Rong TQ, Liu Y, Shao JW (2020) Re-examining the drive forces of China's industrial wastewater pollution based on GWR model at provincial level. J Clean Prod 262:12309.

Zhang W, Ma F, Ren M, Yang FQ (2011) Application with internet of things technology in the municipal industrial wastewater treatment based on membrane bioreactor process. Appl Water Sci 11(3):1-12.

Zhang Y, Wu FP (2015) Study on the effect of decomposition factors of industrial wastewater discharge in China based on LMDI Method. Ind Econ Res 6:99-110 (in Chinese).

Zhang Y, Shuai CY, Bian J, Chen X, Wu Y, Shen LY (2019) Socioeconomic factors of PM2.5 concentrations in 152 Chinese cities: Decomposition analysis using LMDI. J Clean Prod 218:96-107.

Zhou X, Sun H (2013) The industrial wastewater emissions and economic growth in regional differentiation in China. J Arid Land Resour Environ 27(12):15-19 (in Chinese).

Zhuang RL, Mi KN, Liang LW (2018) China's industrial wastewater discharge pattern and its driving factors. Resour Environ Yangtze Basin 27(8):1765-1775 (in Chinese). 


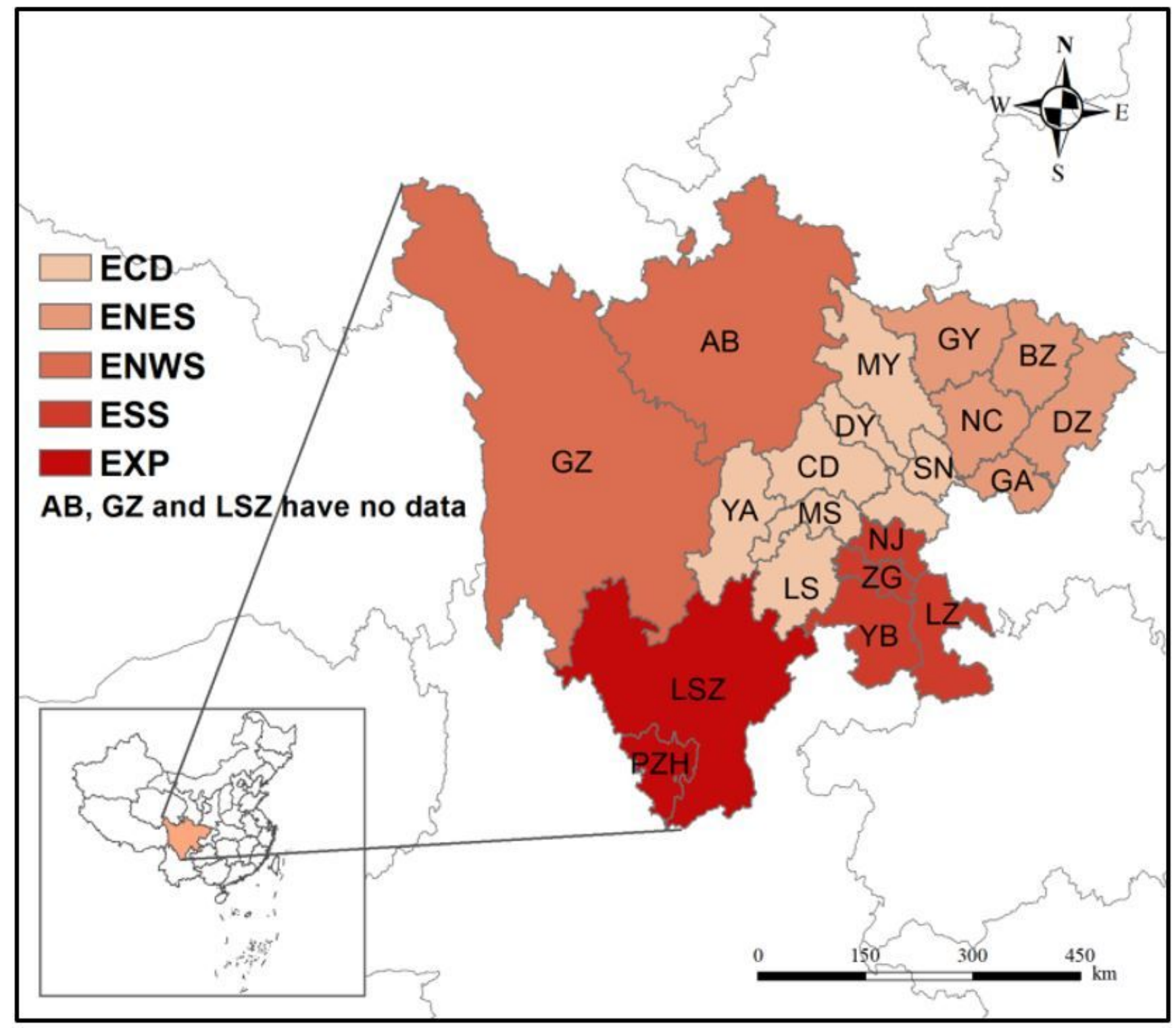

\section{Figure 1}

Study area of Sichuan Province, China. CD (chengdu), DY(deyang), MY (mianyang), LS (leshan), MS (meishan), ZY (ziyang), SN (suining), YA (ya'an), ZG (zigong), LZ (luzhou), NJ (neijing), YB (yibin), GY (guangyuan), NC (nanchong), GA (guang'an), DZ (dazhou), BZ (bazhong), PZH (panzihua), LS (liangshanzhou), BA (a'bazhou) and GZ (ganzizhou). ECD (chengdu plain economic zone, including CD, DY, MY, LS, MS, ZY, SN and YA), ESS (southern sichuan economic zone, including ZG, LZ, NJ and YB), ENES (northeast sichuan economic zone, including GY, NC, GA, DZ and BZ), EXP (panxi economic zone, including PZH and LS) and ENWS (northwest sichuan ecological economic zone, including BA and GZ). 


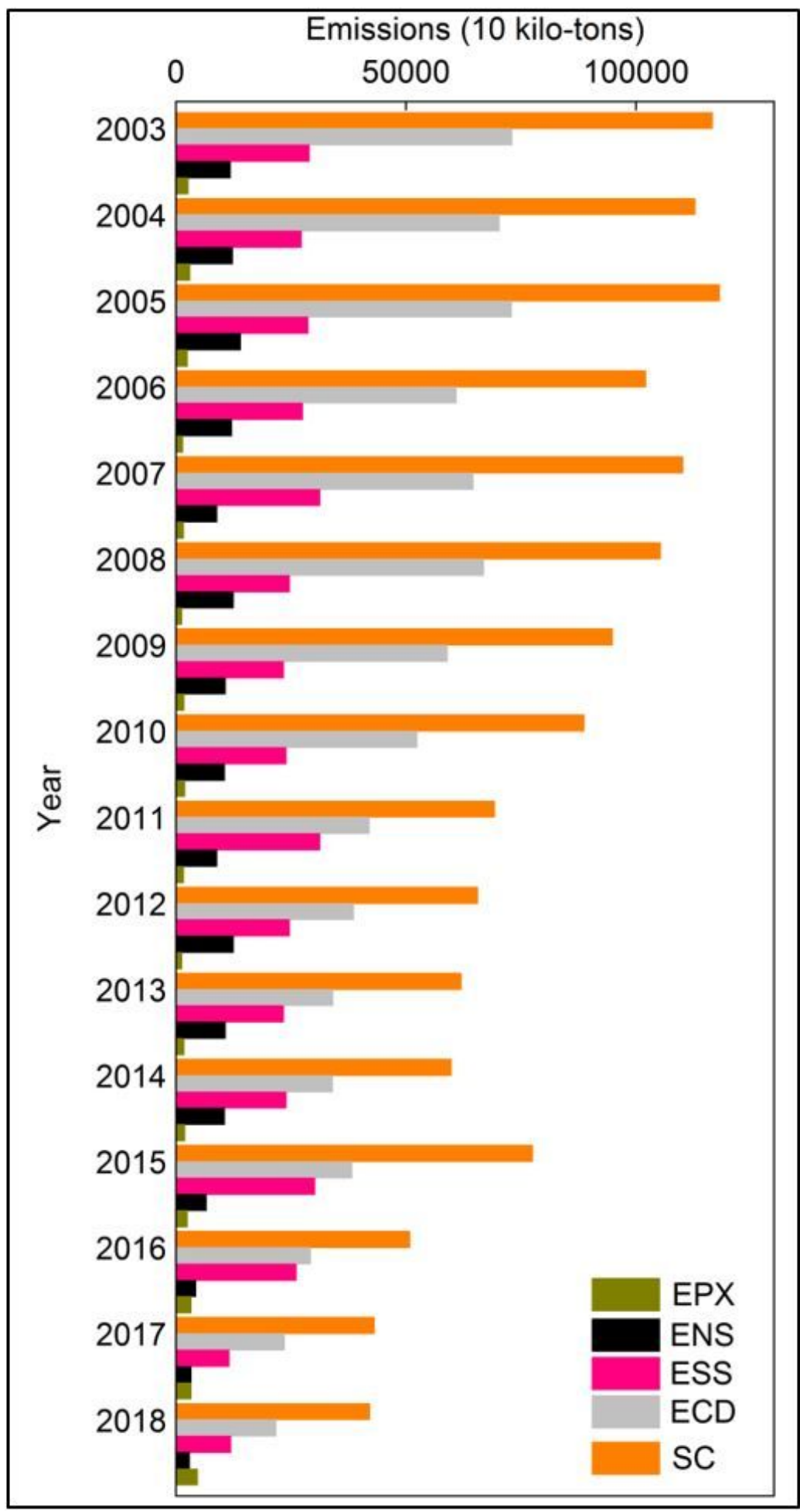

Figure 2

The industrial wastewater discharge in 2003-2018 of Sichuan Province, China. 


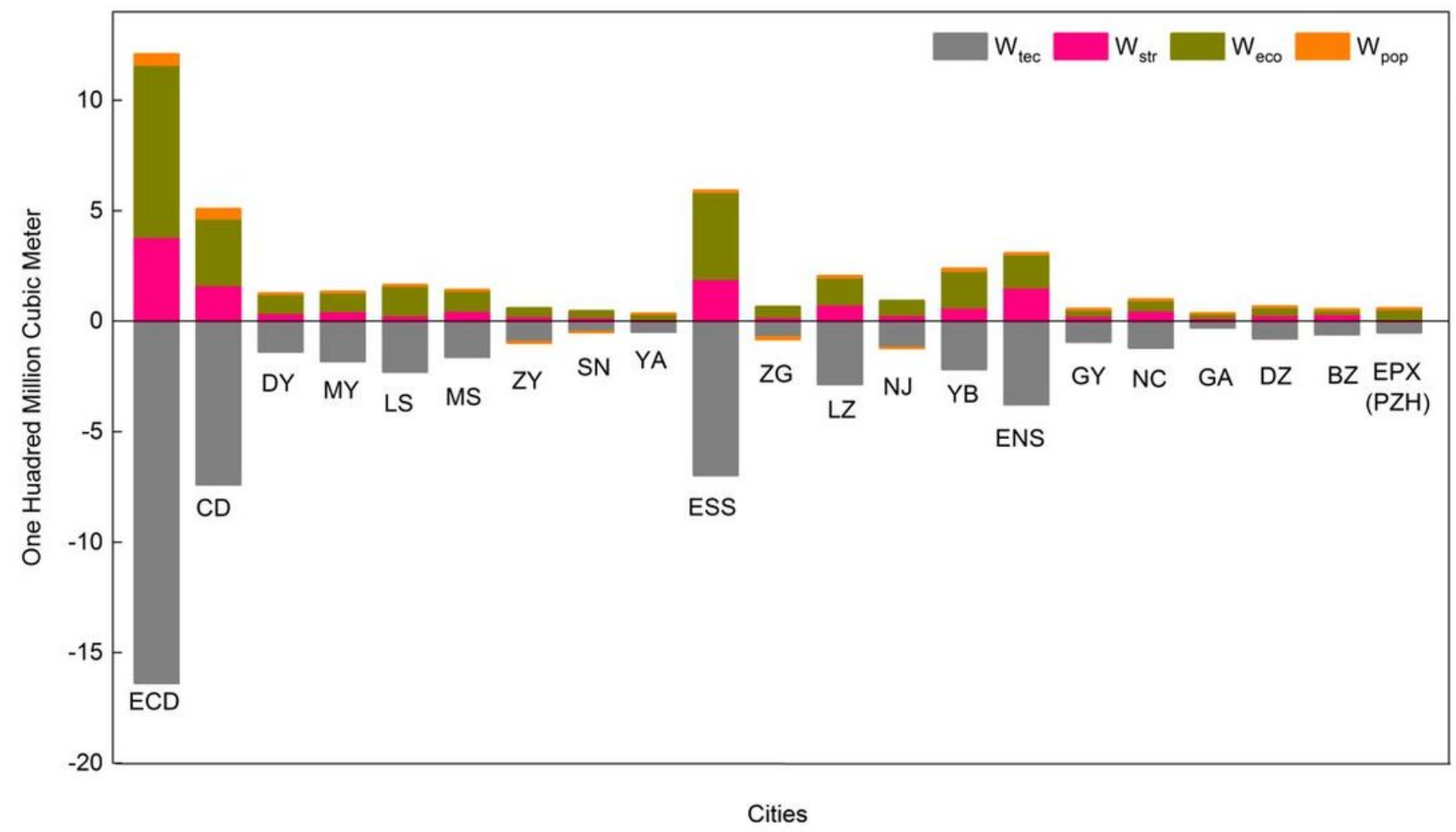

Figure 3

Decomposition analysis results of industrial wastewater discharge in 2003-2018 of Sichuan Province, China.

\section{Supplementary Files}

This is a list of supplementary files associated with this preprint. Click to download.

- TableS1.docx 